\title{
SUBSTRATE TO NOZZLE DISTANCE INFLUENCE ON THE PROPERTIES OF ZINC OXIDE FILMS FORMED WITH CHEMICAL SPRAY PYROLYSIS TECHNIQUE
}

\author{
Halo Dalshad Omar \\ Department of Physics, Faculty of Science and Health, Koya University, University Park, Danielle \\ Mitterrand Boulevard, Koya KOY45, Kurdistan Region-F.R. Iraq \\ halo.dalshad@koyauniversity.org
}

\begin{abstract}
In this work, the zinc oxide $(\mathrm{ZnO})$ thin films have been deposited on the substrate glass via chemical spray pyrolysis technique that influence of the distance between nozzle and substrate on the optical, morphology, chemical composition and structural properties of two samples. Thicknesses of two samples were obtained around $300(\mathrm{~nm})$ via weighing method at a stable substrate temperature of 370 ${ }^{\circ} \mathrm{C}$. Crystal structure was investigated by manner of an X-Ray Diffraction (XRD); it was found that two films have three peaks located at $2 \theta \approx 32.698^{\circ}, 34.185^{\circ}$ and $36.185^{\circ}$ with hkl (100), (002) and (101), respectively. XRD pattern appeared the present of hexagonal crystal structure with (002) arrangement and polycrystalline for two samples. Optical properties of $\mathrm{ZnO}$ thin films were contained study of transmittance spectrum in the extent of the wave length $\lambda(200-1100) \mathrm{nm}$ with using ultraviolet-visible spectrophotometer that varies between 89-92 \%. The results of optical band gap was varied between 2.97 and $3.02(\mathrm{eV})$ along with variable distance between substrate and nozzle 20 and 30 (cm) respectively. The morphology of surface zinc oxide was investigated by scanning tunneling microscopic (STM) and root mean square (rms) of the surface films was measured via STM. XRF spectral measurement confirms and indicates that elements present in the thin films.
\end{abstract}

Keywords: Spray pyrolysis, ZnO thin films, morphology, structure and optical properties and XRF

\section{Introduction}

$\mathrm{ZnO}$ is one of the significant semiconductor materials belonging to II-VI group [1]. These properties determine most technological applications for instance, zinc oxide (ZnO) based 
materials have been used with photovoltaic cell materials, photonics and sensing. For fabrication of the zinc oxide films on substrate of glass and low cost by chemical spray pyrolysis technique. There are some factors that may influence the physical properties with chemical spray pyrolysis technique stage include the spray temperature, the spray rate, the spraying geometry and the distance between substrate and nozzle [1, 2]. Substrate of glass was used to fabricate the film coating [3], which is known an essential droplet distance at spray technique. Though 20 (cm) substrate-nozzle distance is not a valid distance for a good crystalline and $30(\mathrm{~cm})$ substratenozzle distance is the best crystalline in this system. In present work, thin films were influence by the substrate-to-nozzle distances at constant substrate temperature $370{ }^{\circ} \mathrm{C}$ and concentration of $0.1 \mathrm{M}$ [1]. The structural of the two samples were detected with X-ray diffraction and also the optical properties were determined via a spectrophotometer [3, 4]. In addition, morphology surface of zinc oxide thin films was studied by Scanning Tunneling Microscope (STM). Finally, the peaks of XRF are correspond to the elements in the samples [5], in which, the energy of the thin films depends on the detector efficiency.

\section{Experimental details}

Zinc oxide thin films were deposited onto the glass substrate via the chemical spray pyrolysis technique [1]. It was cleaned first by acetone, and then dried by optical cleaning paper [6]. Solution of chemical spray pyrolysis was prepared by using zinc acetate $\mathrm{Zn}\left(\mathrm{CH}_{3} . \mathrm{COO}\right)_{2} .2 \mathrm{H}_{2} \mathrm{O}=$ $219.49(\mathrm{gm} / \mathrm{mol})$ and $99.9 \%$ purity at a constant substrate temperature of $370{ }^{\circ} \mathrm{C}$; molarities of $0.1 \mathrm{M}$ and appropriate volumes by a distilled water [2, 6, 7]. Two samples have various distances between substrate and nozzle was and maintained at 20 and $30(\mathrm{~cm})$ as shown in Figure 1. The spray rate was about 2 minute. The carrier gas used for spraying was compressed nitrogen $\left(\mathrm{N}_{2}\right)$ gas at a pressure of 1 bar and $\mathrm{Zn}\left(\mathrm{CH}_{3} . \mathrm{COO}\right)_{2} .2 \mathrm{H}_{2} \mathrm{O}$ dissolved via heating as seen in the Eq. $1[7,8]$.

$\mathrm{Zn}\left(\mathrm{CH}_{3} \mathrm{COO}\right)_{2} \cdot 2 \mathrm{H}_{2} \mathrm{O}+\mathrm{H}_{2} \mathrm{O} \rightarrow \mathrm{ZnO} \downarrow+2 \mathrm{H}_{2} \mathrm{O} \uparrow+2 \mathrm{CH}_{3} \mathrm{COOH} \uparrow$

The film thickness was measured by the weighting-method via a digital balance type (Meter AE160) with susceptibility of $10^{-4}$ (gm), and the thickness was calculated according to the Eq. 2 [9].

$T=\frac{\Delta m}{A \rho}$

where $\mathrm{T}$ is defined as the thickness of the film, $\Delta \mathrm{m}$ is weight difference of substrate, and $\Delta \mathrm{m} \approx$ 0.0029 (gm) is the mass difference of slide after and before the deposition. A is area $A=2.35 \times$ $7.2\left(\mathrm{~cm}^{2}\right)$ were used as glass substrates and density $\rho=5.606\left(\mathrm{gm} / \mathrm{cm}^{3}\right)$.

The thicknesses of two samples about $300(\mathrm{~nm})$ were found to be 30 and $20(\mathrm{~cm})$. Shows went up with distance between nozzle and substrate $[1,10]$. 


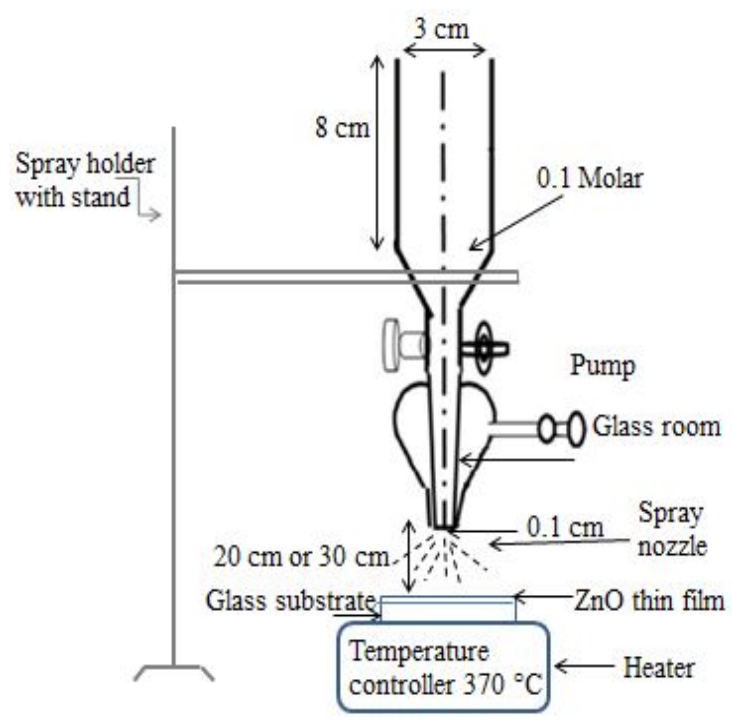

Figure 1. Schematic of the spray pyrolysis system

X-ray diffraction (XRD) technique was used to analysis of the prepared of Zinc oxide (ZnO) thin film via a (Model:Panalytical Empyrean) with $45(\mathrm{kV})$ and $40(\mathrm{~mA})$ and using copper-K $\mathrm{K}_{\alpha}$ radiation by wavelength at $0.15460(\mathrm{~nm}) \mathrm{X}$-ray source [5]. Data of X-ray diffraction was received of the $2 \theta$ area from 5 to 70 degrees with a step of $0.013 \mathrm{deg}$. Furthermore, optical properties of the thin films were estimated by UV (Model: UV-1240, Shimadzu) spectrometer and the wavelength $\lambda$ range between 200 and $1100(\mathrm{~nm})$. In surface topography by scanning tunneling microscope (Model: NT-MDT Solver Nano), a small voltage of $2.90(\mathrm{nV})$ and a current of 4.825 (nA) was applied on the probe (tip) over $3 \times 2.5 \mu \mathrm{m}$ area by semi-contact mode. X-ray fluoresces (Model: Rigaku-NEX CG) can be used to measure the elements of chemical composition of two samples. The X-ray tube current and voltage were applied approximately 1 $(\mathrm{mA})$ and $25(\mathrm{kV})$ respectively [11]. All measurement were used four target but the target of the molybdenum (Mo) was a better than another target such as $\mathrm{RX} 9, \mathrm{Cu}$ and $\mathrm{Al}$ because the intensity by Mo is clearly to determine chemical composition component on the surface thin films. The time of X-ray tube measured 200 (sec) for aluminum and 100 (sec) for Mo, Cu and RX9.

\section{Result and discussion}

\subsection{Structural measurement}

Figure 2, X-ray diffraction patterns of zinc oxide films at various substrate-nozzle to distances; three peaks noticed at $2 \theta \approx 32.698^{\circ}, 34.185^{\circ}$ and $36.185^{\circ}$ were corresponding to (100), (002) and (101) orientations respectively as seen in the Table 1 . XRD study indicated that the films are polycrystalline and hexagonal structure with (002) peak also determined from the inter-planar spacing of (hkl) planes Eq. 3 [6, 12, 13]. 
$\frac{1}{d_{h k l}^{2}}=\frac{a\left(h^{2}+h k+l^{2}\right)}{\left(3 a^{2}\right)}+\left(\frac{l^{2}}{c^{2}}\right)$

where a, c are lattice parameters, hkl are the miller indices of the planes, and dhkl is interplanar spacing.

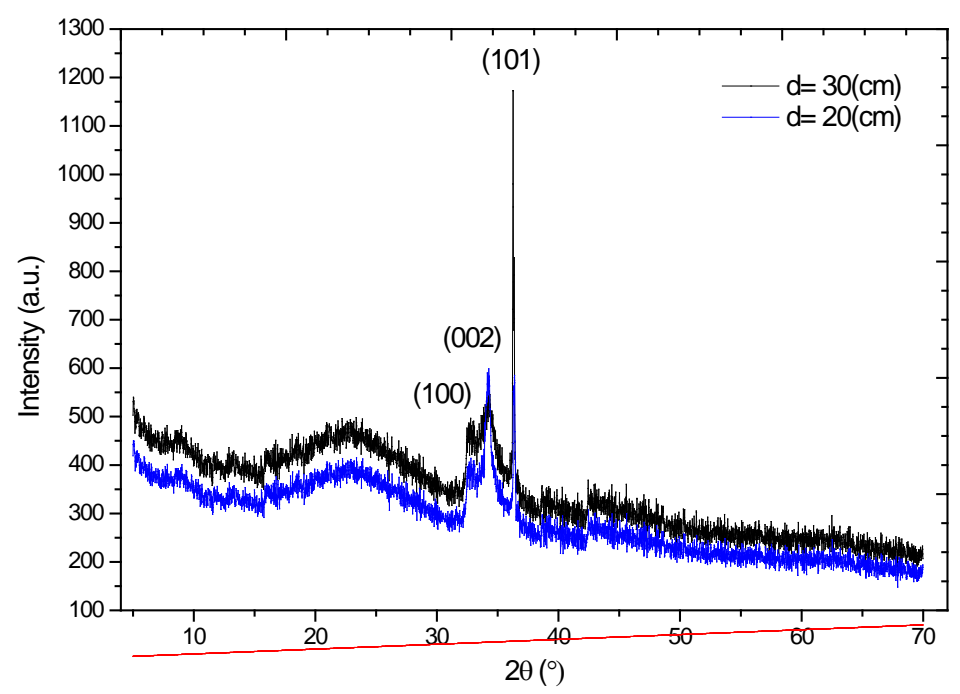

Figure 2. XRD for Zinc oxide films on glass substrate at variant distance between nozzlesubstrate

The distance between nozzle and substrate changes, and the thermal energy in the vapor space modifies which depends importantly on substrate-nozzle distance [10]. The peak intensities of the orientation (hkl) increased with elevating nozzle-substrate distances because at little distance like 20 (cm), droplet in liquid phase onto the substrate and decomposes without a good film growth, when the distance is increased to $30(\mathrm{~cm})$, decreasing droplets and deposition condition taken location and the crystallity increases $[1,14,15]$. The particle size (D) of the polycrystalline material can be calculated from the intensity patterns by X-ray diffraction and using Debye Scherrer's method by the Eq. 4[11, 16, 17].

$D=\frac{0.9 \lambda}{\beta \cos \theta}$

where $\beta$ is define as the full width at half maximum (FWHM) of the XRD peak appearing at the diffraction angle $\theta$ and $\lambda$ is the wavelength, the value of particle size (D) listed in the table 1 .

The dislocation density $(\delta)$ is illustrated the length of dislocation lines per unit volume of the crystal and it was calculated via the Eq. 5 [14, 18, 19].

$\delta=\frac{1}{D^{2}}$

In the table 1 , the particle size is increasing with increasing the nozzle-substrate distance at 30 
$(\mathrm{cm})$, and the dislocation density should be decreasing along with the length of dislocation per unit volume and measure of the quantity defects in a crystal $\mathrm{ZnO}[10,14,18]$.

Table 1. The $2 \theta$ values, inter-planar spacing, crystallite size and dislocation density of $\mathrm{ZnO}$ for the distance 20 and $30(\mathrm{~cm})$ between nozzle-substrate

\begin{tabular}{|c|c|c|c|c|c|}
\hline $\begin{array}{c}\text { Distance } \\
\text { between } \\
\text { nozzle- } \\
\text { substrate } \\
(\mathrm{cm})\end{array}$ & $\begin{array}{c}\text { Miller } \\
\text { indices } \\
(\mathrm{hkl})\end{array}$ & $2 \theta\left(^{\circ}\right)$ & $\begin{array}{c}\text { Inter- } \\
\text { planner } \\
(\mathrm{d})\left({ }^{\circ} \mathrm{A}\right)\end{array}$ & $\begin{array}{c}\text { Crystallite } \\
\text { Size }(\mathrm{nm})\end{array}$ & $\begin{array}{c}\text { Dislocation } \\
\text { density } \delta \\
\mathrm{x} 10^{14} \\
\text { lines } / \mathrm{m}^{2}\end{array}$ \\
\hline 30 & $(100)$ & 32.698 & 2.822 & 23.02 & 18.9 \\
\hline 20 & $(100)$ & 32.638 & 2.775 & 15.28 & 42.8 \\
\hline 30 & $(002)$ & 34.185 & 2.617 & 31.20 & 10.3 \\
\hline 20 & $(002)$ & 34.263 & 2.567 & 23.17 & 18.6 \\
\hline 30 & $(101)$ & 36.185 & 2.476 & 31.38 & 10.2 \\
\hline 20 & $(101)$ & 36.240 & 2.441 & 29.36 & 11.6 \\
\hline
\end{tabular}

\subsection{Surface morphology}

The surface morphology of zinc oxide thin films was clearly smooth [5]. The valuation of root mean square surface roughness of the thin films was about 17.470 and $10.062(\mathrm{~nm})$ for surface thin films with various distances between substrate and nozzle of 20 and $30(\mathrm{~cm})$ respectively the Figure 3 . The root mean square (rms) increases with decreasing nozzle-substrate distances due to the droplet in liquid onto the substrate decomposes at distances of $20(\mathrm{~cm})$ is not a good film growth but the distance is increased at $30(\mathrm{~cm})$. The deposition is take approximately all location on the substrate and the root mean square roughness reduced on the substrate [4]. 3D views of zinc oxide have been presented by using STM that the size of images $3 \times 2.5(\mu \mathrm{m})$ as shown in Figure 3. The morphology surface has a strong influence on the optical properties for instance transmittance and optical band gap [4].
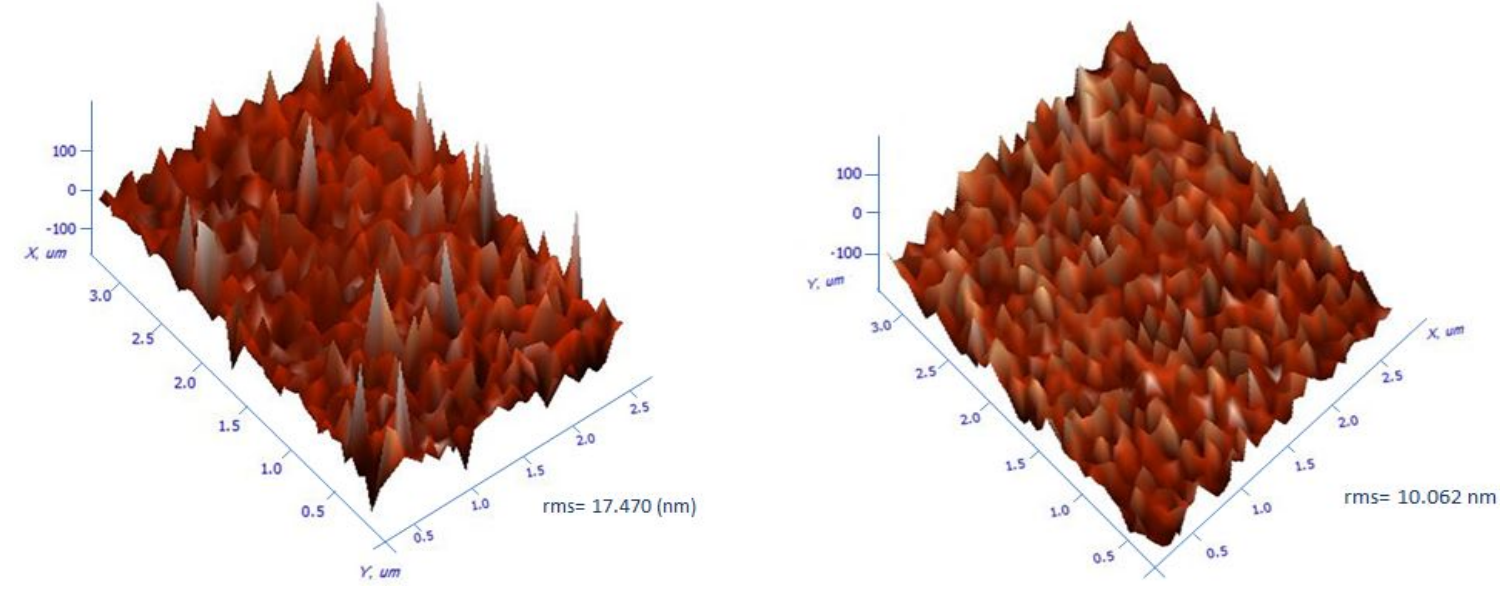

Figure 3. STM analysis of zinc oxide thin films with different nozzle-substrate distances 


\subsection{Optical measurements}

Ultraviolet-visible spectrophotometer (Shimadzu-1240) collected transmittance spectra $\mathrm{T}$ and the wavelength range from 200 to $1100(\mathrm{~nm})$. Transmission is related to absorption coefficient $(\alpha)$ and film thickness (d) was calculated according to Beer's law as shown in Eq. 6 [15, 20, 21].

$\alpha=\frac{1}{d} \ln \frac{1}{T}$

Figure 4 explains the transmission spectra (T) between 200 and 1100 (nm) taken in thin films fabricated by variant distances between substrate and nozzle. An area for powerful transparency is located from 200 to $800(\mathrm{~nm})$. The value of the transmission is around between $89-92 \%$. The transmittance of the films increased via increasing substrate nozzle distance because of an increasing crystallization, decreasing droplets in liquid phase sprayed upwards the substrate at $30(\mathrm{~cm})$, concept deposition condition completed and a good transparency films were obtained. The mechanism of chemical spray pyrolysis technique will be altogether purely $[1,2$, $10,15]$.

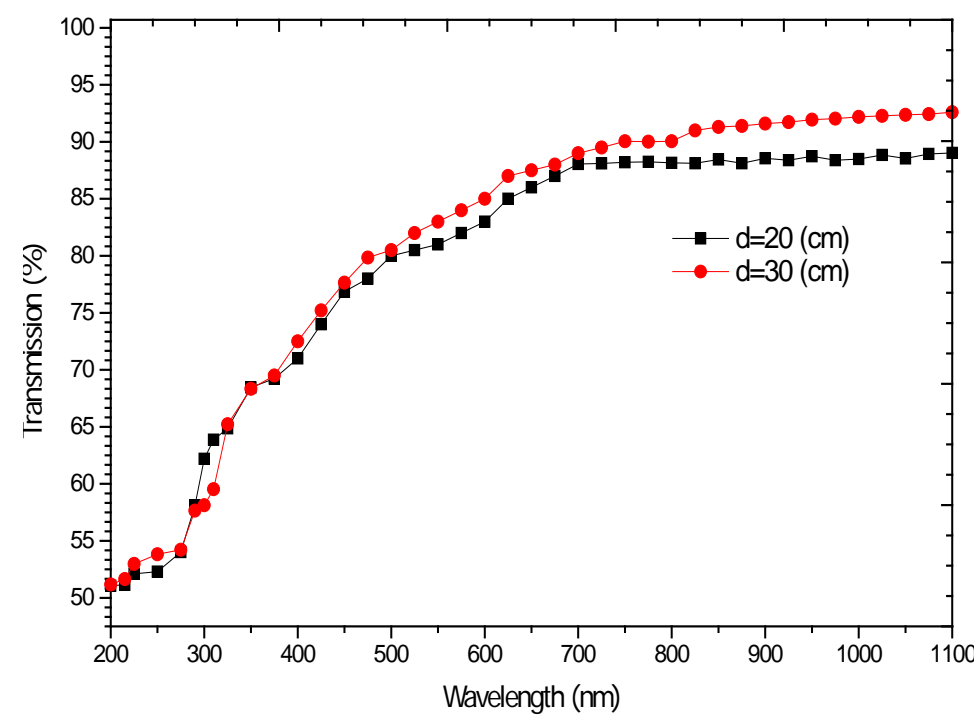

Figure 4. Transmittance versus wavelength for zinc oxide films

Absorption coefficient is related to optical band gap via Tauc's law as shown in Eq. 7 [15, 22].

$(\alpha h v)^{2}=A(h v-E g)$

where $\mathrm{h}$ is Planck's constant $\mathrm{v}$ is the photon frequency, $\mathrm{A}$ is constant and Eg is the band gap of the film. If the plot $(\alpha h v)^{2}$ in function of photon energy $E=h v($ with hv $(\mathrm{eV})=\mathrm{hc} / \lambda=1240 / \lambda)$ ) and with the linear part of $(\alpha h v)^{2}$ to x-coordinate axis (ie., $(\alpha h v)^{2}=0$ ), obtain Eg value [10, 23, 24]. The differentiation for the concluded optical gap of thin films by nozzle-substrate distances are reported in the Figure 5. Optical band gap was increased with an increase in the substratenozzle distance. The values of optical band gap are about 2.97 and $3.02(\mathrm{eV})$, while the variant distances of substrate-nozzle are around 20 and $30(\mathrm{~cm})$. This increase in optical band gap can be 
assigned to and went up in carrier concentration of the thin films presentable to complete decomposition of the deposited $\mathrm{ZnO}$ thin films [2].

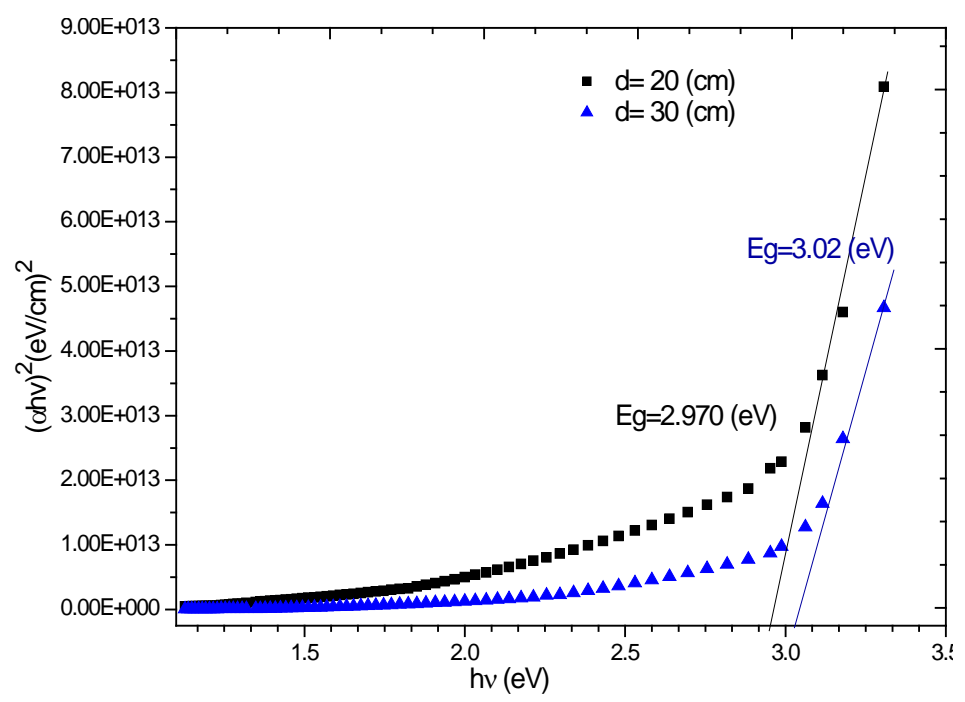

Figure 5. Energy gap of ZnO thin films with different substrate-nozzle distances.

\subsection{XRF Studies}

The presence of peak intensity of zinc is increasing with nozzle-substrate distances from 20 to 30 (cm). As shown in Figure 6, the peak intensities of $\mathrm{Zn}-\mathrm{K}_{\alpha}$ for two samples were increased approximately from 1800 to 3510 (cps) and the peak intensities for $\mathrm{Zn}-\mathrm{k}_{\beta}$ were between 300 and 520 (cps) $[5,11]$.

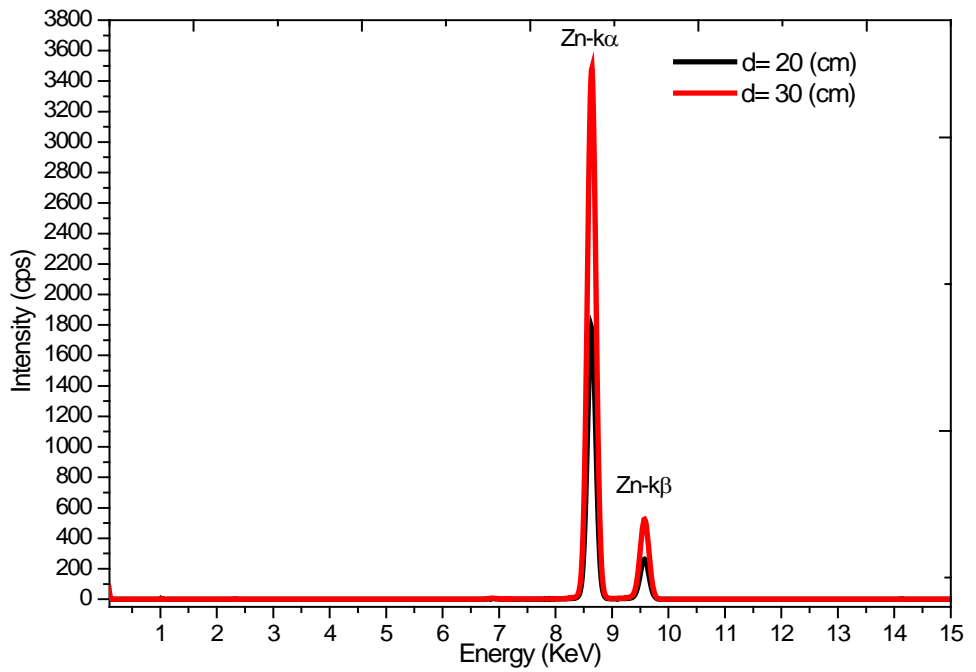

Figure 6. XRF spectrum with various distances nozzle-substrate

The energies of $\mathrm{Zn}-\mathrm{K}_{\alpha}$ and $\mathrm{Zn}-\mathrm{k}_{\beta}$ are corresponding to $8.625(\mathrm{KeV})$ and to $9.570(\mathrm{KeV})$, respectively. The peaks of the oxygen $(\mathrm{O})$ and contamination cannot be investigated by XRF because the detector is not very sensitive to study the energy which these low-atomic number $(\mathrm{Z})$ elements or light elements by X-ray fluorescence peaks. 


\section{Conclusion}

$\mathrm{ZnO}$ thin films were deposited with chemical spray pyrolysis technique. The influence of the distances between nozzle and substrate on the structural, morphology, chemical composition, and optical analysis of thin films were detected. X-ray diffraction pattern confirm of the present of hexagonal structure with (002) orientation for two samples. The optical transmittance value of the samples alterable for the wavelengths range 200-1100 (nm) with approximately between values of $89-92 \%$. The optical band gap values are around 2.97 and $3.02(\mathrm{eV})$, and variant of substratenozzle distances are about 20 and $30(\mathrm{~cm})$. The obtained results proposed that the substratenozzle distance is the most important parameter and the deposited films could be used for photovoltaic cell materials. Morphology of surface thin films was measured by STM and an increase of the root mean square roughness (rms) as a result of decrease of nozzle-substrate distances, where the rms are 17.470 and $10.062(\mathrm{~nm})$ at distance 20 and $30(\mathrm{~cm})$, respectively. The morphology surface has a strong influence on the optical properties for instance transmittance and optical band gap. The presence of zinc is confirmed by XRF. Two samples were indicated that $\mathrm{Zn}-\mathrm{K}_{\alpha}$ corresponding to $8.625(\mathrm{KeV})$, and $\mathrm{Zn}-\mathrm{k}_{\beta} 9.570(\mathrm{KeV})$.

\section{Acknowledgements}

Author is acknowledges Physics department and Koya University for their supporting of this investigation.

\section{References}

[1] Hafdallah, A., Azzedine, A., Belhani, H., Aida, M.S., Attaf, N., "Effect of the NozzleSubstrate Distance on the Structural and Optical Properties of ZnO Thin Films Deposited by Spray Pyrolysis Technique”, American Journal of Nano Research and Applications 5(6) (2017) : 87.

[2] Babar, A.R., Shinde, S.S., Moholkar, A.V., Bhosale, C.H., Rajpure, K.Y., "Structural and optoelectronic properties of sprayed Sb: SnO2 thin films: Effects of substrate temperature and nozzle-to-substrate distance”, Journal of Semiconductors 32(10) (2011) : 102001.

[3] Al-khayatt, A.H.O., Jaafer, M.D., "Characteristics of Nanocrystalline ZnS thin films grown on glass with different $\mathrm{Zn}$ ion concentrations by CBD technique”, Journal of Applied Physics 6(1) (2014) : 27-35.

[4] Meshram, R.S., Suryavanshi, B.M., Thombre, R.M., Chandrapur, D., Gadchiroli, D., "Structural and optical properties of CdS thin films obtained by spray pyrolysis", Adv. Appl. Sci. Res 3 (2012) : 1563-1571.

[5] Faraj, M.G., Chaqmaqchee, F.A.I., Omar, H.D., "Structural, morphological and electrical properties of $\mathrm{Zn}$ doped $\mathrm{PbS}$ thin films by chemical spray pyrolysis", Journal of Optoelectronics and Advanced Materials 19(5-6) (2017) : 412-416.

[6] Gumus, C., Ozkendir, O.M., Kavak, H., Ufuktepe, Y., "Structural and optical properties of zinc oxide thin films prepared by spray pyrolysis method”, Journal of optoelectronics and 
advanced materials 8(1) (2006) : 299.

[7] Jamil, S.S.B., "The optical and structural properties of $\mathrm{ZnO}$ films prepared by spray pyrolysis”, Engineering and Technology Journal 28(20) (2010) : 6061-6073.

[8] Ahmed, G.S., "Study The Effect of Thickness on Zno Thin Films prepared by Spray Pyrolysis Method”, Journal of university of Anbar for Pure science 7(2) (2013).

[9] Bakr, N.A., Salman, S.A., Hameed, S.A., "Deposition and Characterization of $\mathrm{Cu}_{2} \mathrm{ZnSnS}_{4}$ Thin Films for Solar Cell Applications”, International Journal of Applied Engineering Research 13(6) (2018) : 3379-3388.

[10] Turgut, G., Tatar, D., Düzgün, B., "Effect Of Nozzle-Substrate Distance On Electrical, Structural And Optical Properties Of Sno2 Thin Films Prepared By Spray Pyrolysis”, Erzincan Üniversitesi Fen Bilimleri Enstitüsü Dergisi 5(1) (2012) : 13-24.

[11] Omar, H.D., "To Investigation the Structure and Morphology of Iron Metallic by Difference Techniques”, J. Nano. Adv. Mat 3(2) (2015) : 57-61.

[12] Singh, P., Kumar, A., Kaur, D., "Growth and characterization of ZnO nanocrystalline thin films and nanopowder via low-cost ultrasonic spray pyrolysis”, Journal of Crystal Growth 306(2) (2007) : 303-310.

[13] Suhail, A.M., Saeed, N.M., "Preparation and properties of Nanostructure Zinc Oxide Thin Films”, Iraqi Journal of Physics 7(8) (2009) : 75-81.

[14] Hani, M.Y., Al-Aarajiy, A.H., Abdul-Lettif, A.M., "Effect of nozzle to substrate distance on the structural and absorption properties of nickel (II) tetrasulfonated phthalocyanine thin films”, Materials Research Express 5(1) (2018) : 016406.

[15] Koçyiğit, A., Tatar, D., Battal, A., Aydın, S., Turgut, G., Düzgün, B., "Investigation of some properties of SnO2: Sb: F thin films by an economic spray pyrolysis technique". 2013.

[16] Guneri, E., Gumus, C., KIRMIZIGUL, F., "Studies on properties of sprayed SnO2 thin films as a function of substrate-nozzle distance and substrate temperature”, Optoelectronics and Advanced Materials-Rapid Communications (2009) : 383-389.

[17] Omar, H.D., "Intensity Correction and Pole Figure Measurement of Copper Metallic by XRD”, Journal of Basic and Applied Sciences 12 (2016) : 320-322.

[18] Immanuel, P., Prakash, A.A., Mohan, C.R., "Ethanol sensing of V2O5 thin film prepared by spray pyrolysis technique: Effect of substrate to nozzle distance”, In AIP Conference Proceedings: AIP Publishing 1832(1) (2017) : 080022.

[19] Rajalakshmi, P.U., Oommen, R.A.C.H.E.L., Sanjeeviraja, C., "Effect of substrate temperature on the structural, optical and electrical properties of nebulised spray pyrolysed Bi2S3 thin films”, Chalcogenide Lett 8(10) (2011) : 649-657.

[20] Awodugba, A.O., Yusuf, G.T., "Substrate-Nozzle Distance (SND) Influence on the Properties of Fluorine-Doped Tin Oxide Thin Films”. 2017.

[21] Chiu, F.C., "Conduction mechanisms in resistance switching memory devices using transparent boron doped zinc oxide films”, Materials 7(11) (2014) : 7339-7348.

[22] Hasan, N.B., Mohammed, M.A., "Constructing Spray Pyrolysis System For The Preparation of Thin Films and Study The Optical Properties of PbO Films”, International 
Letters of Chemistry, Physics and Astronomy 53 (2015) : 146-153.

[23] Ali, A.I.A., "Molarities effect on structural and optical properties of ZnO prepared by spray pyrolysis”, International Journal of Scientific \& Engineering Research 5(1) (2014) : 2250.

[24] Saleh, A.F., Jaffar, A.M., Samoom, N.A., Mahmmod M.W., "Effect Adding PVA Polymer on Structural and Optical Properties of TiO2 Thin Films”, Al-Nahrain Journal of Science 17(2) (2014) : 161-121. 